\title{
Cryopreservation of expanded mouse blastocysts by vitrification in ethylene glycol-based solutions
}

\author{
S. E. Zhu, M. Kasai*, H. Otoge, T. Sakurai and T. Machida \\ Laboratory of Animal Science, College of Agriculture, Kochi University, Nankoku, Kochi 783, Japan
}

\begin{abstract}
Experiments were conducted to find optimal conditions for obtaining high survival of expanded mouse blastocysts after vitrification. The vitrification solutions used were designated EFS20, EFS30 and EFS40, and contained $20 \%, 30 \%$ and $40 \%$ ethylene glycol, respectively, diluted in PB1 medium containing 30\% Ficoll plus 0.5 mol sucrose $\mathrm{l}^{-1}$. In the toxicity test of the solutions and each cryoprotectant, ethylene glycol was found to be toxic to embryos. For vitrification, expanded blastocysts were exposed to the vitrification solutions at 10,20 or $25^{\circ} \mathrm{C}$ for various periods; they were then cooled rapidly in liquid nitrogen, after which they were warmed rapidly. When the embryos were directly exposed to EFS40 at $20^{\circ} \mathrm{C}$ for $2 \mathrm{~min}$ before vitrification, $66 \%$ of them re-expanded during $48 \mathrm{~h}$ of post-warming culture. The re-expansion rates decreased when exposure time was shortened ( $0.5 \mathrm{~min})$, when exposure temperature was lowered $\left(10^{\circ} \mathrm{C}\right)$, or when embryos were vitrified in EFS20 and EFS30, although these conditions should be less toxic. When embryos had been pretreated in a dilute (10-20\%) ethylene glycol solution for $5 \mathrm{~min}$, followed by short exposure $(0.5 \mathrm{~min})$ to EFS40 at $20^{\circ} \mathrm{C}$, post-vitrification survival rate increased to $83-84 \%$; furthermore, the rate reached $94 \%$ when the temperature was increased to $25^{\circ} \mathrm{C}$. Expanded blastocysts cryopreserved by this two-step method developed into live young as well as control embryos after transfer. The results suggest that permeation of ethylene glycol, possibly into the blastocoel, during pretreatment in a dilute ethylene glycol solution prevented lethal ice formation, while reduced exposure of the embryos to EFS solution decreased toxic injury. It is expected that this simple and efficient method of cryopreservation will be applicable to expanded blastocysts of various species.
\end{abstract}

\section{Introduction}

In recent years, attention has focused on vitrification as a rapid and efficient method for cryopreservation of biological systems (Fahy et al., 1984). The first successful vitrification of mammalian embryos was achieved by Rall and Fahy (1985) with eight-cell mouse embryos. The vitrification solution they used (VS1) was composed of dimethyl sulfoxide (DMSO), acetamide, propylene glycol and polyethylene glycol as cryoprotectants, and embryos were exposed to the solution at a low temperature $\left(4^{\circ} \mathrm{C}\right)$ after stepwise equilibration, to avoid its toxicity. This method was applied to the cryopreservation of mouse embryos at various developmental stages, but the survival of blastocysts was lower than that of eight-cell embryos (Hsu ef al,, 1986; Kono and Tsunoda, 1987; Matsumoto et al., 1987). In addition, manipulating embryos under a microscope at a low temperature was not practical, and the whole procedure before rapid cooling required 25-40 min. Several attempts have therefore been made to improve the vitrification solution and the procedure for embryo treatment (Scheffen et al., 1986; Rall, 1987; Nakagata, 1989; Schiewe et al., 1991).

${ }^{*}$ Correspondence and reprint requests.

Received 8 June 1992.
Mouse morulae have been vitrified by a simple method, without appreciable loss of viability (Kasai et al., 1990). This method using a new vitrification solution based on ethylene glycol, which permeates the cell rapidly and has low toxicity requires embryo treatment for only $2 \mathrm{~min}$ at $20^{\circ} \mathrm{C}$ before the sample is plunged into liquid nitrogen. This simple method developed for morulae was examined to determine whether it was effective for mouse embryos at other developmental stages; it was found that blastocysts with a small blastocoel could also be vitrified without significant decrease in survival $(91 \%)$. As the blastocoel began to enlarge, however, survival decreased, the rate being $57 \%$ in expanded blastocysts (Miyake et al., in press).

In mice, few attempts have been made to cryopreserve expanded blastocysts, even by conventional freezing. However, in livestock embryos, the expanded blastocyst is a stage of great importance. The first successful embryo freezing in cows (Wilmut and Rowson, 1973) and goats (Bilton and Moore, 1976) was accomplished at this stage, and it has been found that embryo tolerance to freezing increases after expansion of the blastocoel in pigs (Nagashima et al., 1989). Furthermore, recent techniques have made it possible to produce expanded cattle blastocysts through an in vitro process of maturation, fertilization and development (Goto et al, 1988; Leibfried-Rutledge et al., 

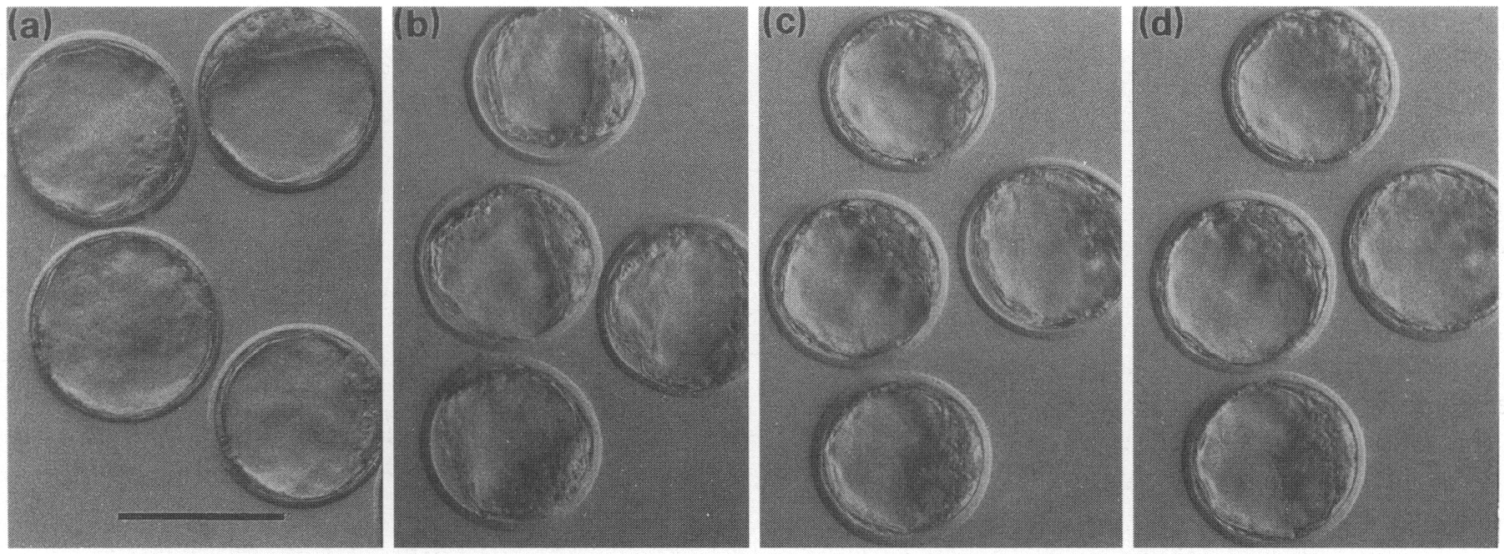

Fig. 1. When fresh expanded blastocysts (a) were suspended in PB1 medium containing $20 \%(\mathrm{v} / \mathrm{v})$ ethylene glycol at $20^{\circ} \mathrm{C}$, the embryos shrank within the zona pellucida, and the zona also slightly decreased in diameter. After 2 min of suspension, the embryos were still shrinking (b), but after $5 \mathrm{~min}$ (c) and $10 \mathrm{~min}$ (d), they had generally re-expanded within the zona. Bar: $100 \mu \mathrm{m}$.

1989; Gordon and Lu, 1990). However, attempts to vitrify bovine blastocysts have been disappointing (Massip et al., 1986; Douchi $e t$ al., 1990). Survival of mouse blastocysts after cryopreservation has also been lower than that of eight-cell embryos to morulae, not only with various methods of vitrification (Scheffen et al., 1986; Bielanski, 1987; Kono and Tsunoda, 1987; Matsumoto et al., 1987; Nakagata, 1989; Valdez et al., 1990), but also with conventional freezing (Whittingham et al., 1972; Massip ef al., 1984). The present study was conducted to find optimal conditions for obtaining high survival of expanded mouse blastocysts, as a model for embryos with a large blastocoel, after vitrification in solutions based on ethylene glycol.

\section{Materials and Methods}

\section{Collection of expanded blastocysts}

Female ICR mice (6-12 weeks old, CLEA Japan, Inc., Tokyo) kept under a $14 \mathrm{~h}$ light:10 h dark cycle were mated with ICR or BDFI $(\mathrm{C} 57 \mathrm{BL} / 6 \mathrm{~N} \times \mathrm{DBA} / 2 \mathrm{~N})$ male mice. Some of the females were mated naturally, but others were induced to superovulate with i.p. injections of 5 iu PMSG (Serotropin: Teikokuzoki, Tokyo) and 5 iu hCG (Puberogen: Sankyozoki, Tokyo) given $48 \mathrm{~h}$ apart. Morulae and expanded blastocysts were collected in modified phosphate-buffered saline (PB1) (Whittingham, 1971) from the uteri of mated animals at 78-80 and 95-100 h, respectively, after the presumed endogenous LH surge (in naturally mated animals) or hCG injection (in superovulated animals). Morulae and unexpanded blastocysts were cultured in a modified Krebs-Ringer-bicarbonate (KRB) medium (Toyoda and Chang, 1974) for 3-40 h under paraffin oil in a culture dish in a $\mathrm{CO}_{2}$ incubator $\left(5 \% \mathrm{CO}_{2}\right.$ in air at $\left.37^{\circ} \mathrm{C}\right)$. Embryos were used when they had developed into expanded blastocysts, which had an apparently expanded blastocoel and zona pellucida, but were not hatching or had not hatched from the zona (Fig. 1a). Thus, the effects of embryonic age, which ranged from 95 to $120 \mathrm{~h}$ after $\mathrm{LH} / \mathrm{hCG}$, were disregarded.

\section{Vitrification solutions}

Ethylene glycol was diluted to 20,30 and $40 \%(\mathrm{v} / \mathrm{v})$ in PB1 medium containing $30 \%(\mathrm{w} / \mathrm{v})$ Ficoll 70 (average molecular weight 70000 ; Pharmacia, Uppsala) plus $0.5 \mathrm{~mol}$ sucrose $1^{-1}$. The respective solutions were designated EFS20, EFS30 and EFS40, after the initials of the three cryoprotectants together with the concentration of ethylene glycol. Although the final molar concentrations of Ficoll and sucrose in the three solutions were different, their molal concentrations remained constant. When these solutions were aspirated in a $0.25 \mathrm{ml}$ plastic straw (I.M.V., L'Aigle) and transferred into liquid nitrogen, they all remained transparent; on being transferred to $20^{\circ} \mathrm{C}$ water, EFS40 remained transparent, whereas EFS30 and EFS20 became opaque, which was a sign of devitrification.

\section{Toxic effects of cryoprotectants on expanded blastocysts}

Cryoprotectant-induced injury during exposure was examined by suspending ten expanded blastocysts in $100 \mu \mathrm{l}$ of an EFS solution (EFS20, EFS30 or EFS40), or in PB1 medium containing a constituent cryoprotectant, under paraffin oil in a culture dish at $20 \pm 0.5^{\circ} \mathrm{C}$; they were kept there for $2,5,10$ or $20 \mathrm{~min}$. Cryoprotectants tested were $20 \%, 30 \%$ and $40 \%(\mathrm{v} / \mathrm{v})$ ethylene glycol, $50 \%(\mathrm{w} / \mathrm{v})$ Ficoll, $1.0 \mathrm{~mol}$ sucrose $\mathrm{I}^{-1}$, and $30 \%$ Ficoll plus 0.5 mol sucrose $\mathrm{I}^{-1}$. Without being cooled, embryos in EFS solutions were transferred to PB1 medium containing $0.5 \mathrm{~mol}$ sucrose $\mathrm{l}^{-1}$ (S-PB1) and then to fresh PB1 medium, at $5 \mathrm{~min}$ intervals, at $20^{\circ} \mathrm{C}$. Embryos in ethylene glycol were transferred to PB1 medium containing the same concentration of ethylene glycol plus 0.5 mol sucrose $\mathrm{l}^{-1}$, then to S-PB1, and then to fresh $\mathrm{PB1}$, at $5 \mathrm{~min}$ intervals. Those in Ficoll or sucrose were transferred directly to fresh PB1 medium. Experiments were replicated 3-4 times for each treatment.

\section{Vitrification of expanded blastocysts}

Embryos were vitrified by the procedure described by Kasai et al. (1990), with some modifications. A large column (about 
$55 \mathrm{~mm}$ ) of S-PBI medium, and two columns (about 3 and about $13 \mathrm{~mm}$ ) of EFS solution (EFS20, EFS30 or EFS40) were aspirated in a $0.25 \mathrm{ml}$ plastic straw and separated by air; the straw was then kept horizontal at $10 \pm 1,20 \pm 0.5$ or $25 \pm 0.5^{\circ} \mathrm{C}$.

In the first series of vitrification experiments, expanded blastocysts were exposed to EFS solutions in one step from PB1 medium. In the second series of experiments, however, embryos were vitrified by a two-step method; embryos were first pretreated by suspension in PB1 medium containing $10 \%, 20 \%$ or $30 \%(\mathrm{v} / \mathrm{v})$ ethylene glycol at $20 \pm 0.5$ or $25 \pm 0.5^{\circ} \mathrm{C}$ for 5 or $10 \mathrm{~min}$ before being exposed to EFS solutions.

When the embryos were vitrified after 0.5 or $1 \mathrm{~min}$ of exposure to an EFS solution, they were directly transferred to the larger column of the EFS solution (about $13 \mathrm{~mm}$ ) via a pipette, with a small volume (about $0.2 \mu \mathrm{l}$ ) of PBI medium (one-step method) or PBI medium containing 10-30\% ethylene glycol (two-step method). When the exposure time to EFS solution before vitrification was 2 or $5 \mathrm{~min}$, the embryos were first suspended in the same EFS solution in a watch glass, washed in the solution twice, and then transferred to the EFS column in the straw.

The EFS solution (about $3 \mathrm{~mm}$ ) and S-PB1 medium (about $12 \mathrm{~mm}$ ) were then aspirated and separated by air, before being sealed with straw powder. About ten embryos were loaded in each straw. The configuration of the straw was described by Kasai et al. (1990). At 0.5, 1, 2 or $5 \mathrm{~min}$ after exposure of the embryos to EFS solution, the straws were plunged into a Dewar vessel (inner diameter $100 \mathrm{~mm}$ ) containing $5-7 \mathrm{~cm}$ depth of liquid nitrogen, so as to immerse about half of the straw, which included the EFS solution (powder side), in liquid nitrogen; the rest of the straw, including the larger column of S-PBI (cotton plug side) was in the gas. This method of cooling prevented the bursting of straws caused by rapid freezing of the large column of S-PBI medium. After being kept in the Dewar vessel for at least $1 \mathrm{~min}$, straws were stored in a liquid nitrogen tank.

For embryo recovery, straws treated at 10 and $20^{\circ} \mathrm{C}$ were warmed rapidly in water at $20^{\circ} \mathrm{C}$, and those treated at $25^{\circ} \mathrm{C}$ were warmed in water at $25^{\circ} \mathrm{C}$. As soon as the crystallized SPBI medium in the straw began to melt (about $5 \mathrm{~s}$ ), the contents of the straw were expelled into a watch glass by flushing the straw with about $0.8 \mathrm{ml} \mathrm{S-PB1}$ medium at the same temperature as the water. The embryos were then pipetted into fresh S-PB1 medium. At about $5 \mathrm{~min}$ after being flushed out, the embryos were transferred to fresh PB1 medium. Experiments were replicated at least four times for each treatment.

\section{Assessment of survival}

Treated embryos were washed in KRB medium and cultured in about $0.2 \mathrm{ml}$ of the medium under paraffin oil in a culture dish in a $\mathrm{CO}_{2}$ incubator at $37^{\circ} \mathrm{C}$. They were examined at 10 - to $16-\mathrm{h}$ intervals and at $48 \mathrm{~h}$; the criteria for in vitro survival was reexpansion of the blastocoel (A) within $16 \mathrm{~h}$ and (B) within $48 \mathrm{~h}$ of culture. As a control, fresh expanded blastocysts were cultured after being kept in PB1 medium for $30 \mathrm{~min}$ at 10,20 and $25^{\circ} \mathrm{C}$.

Embryos from pigmented mice (ICR $\times$ BDF1) were used to examine their developmental potential in vivo. After recovery from vitrification, embryos were cultured in KRB medium for 3-9 h, and five or six re-expanded blastocysts were transferred to each uterine horn of recipient mice (10-12 embryos per animal). As a control, fresh expanded blastocysts were transferred likewise. Recipients were female ICR mice on day 3 of pseudopregnancy, which had been induced by mating them with vasectomized ICR males (day I was the day the copulation plug was found in the morning). The recipients were allowed to produce litters.

\section{Statistical analysis}

Survival rate after each treatment was compared with that in the control group, with $\chi^{2}$ tests; when expected frequency was less than 5, Fisher's exact probability test was used. In the vitrification of embryos, the data were further analysed by analysis of variance to determine the significance of treatments and the interaction between them; for the analysis, the percentage of embryos that survived was transformed to radians to normalize the results.

\section{Results}

\section{Toxicity test}

When embryos were exposed to vitrification solutions containing various concentrations of ethylene glycol at $20^{\circ} \mathrm{C}, 93-$ $100 \%$ of the embryos could re-expand their blastocoel during culture (for $16 \mathrm{~h}$ and $48 \mathrm{~h}$ ) after 5-10 min exposure to EFS20 and EFS30 (Table 1). With EFS40, however, the survival assessed during $16 \mathrm{~h}$ of culture began to decrease after only $2 \mathrm{~min}$ of exposure $(80 \%)$. Quite similar events were observed when embryos were treated in PBI medium containing the same concentration of ethylene glycol alone; the survival decreased with increasing concentrations of ethylene glycol (Table 2). On the other hand, when embryos were suspended in PB1 medium containing $50 \%$ Ficoll, $1.0 \mathrm{~mol}$ sucrose $\mathrm{l}^{-1}$, or $30 \%$ Ficoll plus $0.5 \mathrm{~mol}$ sucrose $\mathrm{l}^{-1}$ for $20 \mathrm{~min}, 100 \%$ (50 of 50 ), $94 \%$ (47 of 50 ) and $96 \%$ (48 of 50 ), respectively, of the embryos re-expanded within $16 \mathrm{~h}$ of the following culture, and all the embryos regained their volume within $48 \mathrm{~h}$.

\section{Vitrification of embryos}

The survival of embryos after vitrification in EFS solutions in one step is summarized in Table 3. For analysis of variance, data for EFS20, which resulted in very low levels of survival, were excluded, because the solution was not evaluated at $10^{\circ} \mathrm{C}$. In the survival rate, assessed by the re-expansion of the blastocoel during $48 \mathrm{~h}$ of culture, there was an interaction among exposure temperature, vitrification solution and exposure time $(P<0.05)$. The highest survival rate $(66 \%)$ was obtained when embryos were vitrified after 2 min of exposure to EFS40 at $20^{\circ} \mathrm{C}$. Further exposure $(5 \mathrm{~min})$ to the solution decreased survival, as expected from the results of the toxicity test (Table 1 ). The survival rates of vitrified embryos were also reduced, when they were exposed for a shorter period $(0.5 \mathrm{~min})$ and when they were vitrified in EFS20 and EFS30. Embryos were exposed to another low toxic condition, EFS solutions at $10^{\circ} \mathrm{C}$. Postwarming survival rate, assessed by 48 -h culture, increased up to $50-51 \%$ as the duration of the exposure increased. The proportions of embryos that had re-expanded during $16 \mathrm{~h}$ of culture were low in any treatment $(0-31 \%)$, and by this criterion, 
Table 1. Percentage survival of expanded mouse blastocysts exposed to various vitrification solutions at $20^{\circ} \mathrm{C}^{*}$

\begin{tabular}{|c|c|c|c|c|c|c|}
\hline \multirow{3}{*}{$\begin{array}{l}\text { Vitrification } \\
\text { solution }\end{array}$} & \multicolumn{6}{|c|}{ Exposure time } \\
\hline & \multicolumn{2}{|c|}{$2 \min$} & \multicolumn{2}{|c|}{$5 \mathrm{~min}$} & \multicolumn{2}{|c|}{$10 \mathrm{~min}$} \\
\hline & A & B & A & B & A & B \\
\hline EFS20 & 100 & $100(30)$ & 100 & $100(30)$ & 100 & $100(40)$ \\
\hline EFS30 & 100 & $100(30)$ & 100 & $100(40)$ & 93 & $95(40)$ \\
\hline EFS40 & $80^{\mathrm{a}}$ & $90(40)$ & $13^{\mathrm{a}}$ & $18^{a}(40)$ & $0^{a}$ & $30^{a}(30)$ \\
\hline
\end{tabular}

*Survival was assessed by determining the percentage of blastocysts re-expanded (A) within $16 \mathrm{~h}$ and (B) within $48 \mathrm{~h}$ of culture. Figures in parentheses are the numbers of blastocysts treated.

${ }^{2} P<0.01$; significantly different from control, in which $100 \%$ (40 of 40 ) of embryos survived after being kept at $20^{\circ} \mathrm{C}$ for $30 \mathrm{~min}$.

Table 2. Percentage survival of expanded mouse blastocysts exposed to PB1 medium containing various concentrations of ethylene glycol at $20^{\circ} \mathrm{C}^{*}$

\begin{tabular}{|c|c|c|c|c|c|c|}
\hline \multirow{3}{*}{$\begin{array}{l}\text { Concentration of } \\
\text { ethylene glycol } \\
(\%)\end{array}$} & \multicolumn{6}{|c|}{ Exposure time } \\
\hline & \multicolumn{2}{|c|}{$2 \min$} & \multicolumn{2}{|c|}{$5 \mathrm{~min}$} & \multicolumn{2}{|c|}{$10 \mathrm{~min}$} \\
\hline & A & B & A & B & A & $B$ \\
\hline 20 & 100 & $100(30)$ & 100 & $100(40)$ & 100 & $100(40)$ \\
\hline 30 & 100 & $100(30)$ & 100 & $100(40)$ & $83^{\mathrm{a}}$ & $90(40)$ \\
\hline 40 & 100 & $100(40)$ & $25^{2}$ & $25^{\mathrm{a}}(40)$ & $0^{\mathrm{a}}$ & $0^{a}(40)$ \\
\hline
\end{tabular}

*Survival was assessed by determining the percentage of blastocysts re-expanded (A) within $16 \mathrm{~h}$ and (B) within $48 \mathrm{~h}$ of culture. Figures in parentheses are the numbers of blastocysts treated.

. $p<0.01$; significantly different from control, in which $100 \%$ (40 of 40 ) of embryos survived after being kept at $20^{\circ} \mathrm{C}$ for $30 \mathrm{~min}$.

Table 3. Percentage survival of expanded mouse blastocysts vitrified in various solutions after one-step exposure to various vitrification solutions at 10 and $20^{\circ} \mathrm{C}^{*}$

\begin{tabular}{|c|c|c|c|c|c|c|c|}
\hline \multirow{3}{*}{$\begin{array}{l}\text { Exposure } \\
\text { temperature }\end{array}$} & \multirow{3}{*}{$\begin{array}{l}\text { Vitrification } \\
\text { solution }\end{array}$} & \multicolumn{6}{|c|}{ Exposure time } \\
\hline & & \multicolumn{2}{|c|}{$0.5 \mathrm{~min}$} & \multicolumn{2}{|c|}{$2 \min$} & \multicolumn{2}{|c|}{$5 \mathrm{~min}$} \\
\hline & & A & $\mathrm{B}$ & A & B & A & B \\
\hline \multirow[t]{3}{*}{$20^{\circ} \mathrm{C}$} & EFS20 & 0 & $0(41)$ & 7 & $12(41)$ & 0 & $6(35)$ \\
\hline & EFS30 & 4 & $4(46)$ & 26 & $48(42)$ & 10 & $33(40)$ \\
\hline & EFS40 & 31 & $47(45)$ & 24 & $66(50)$ & 6 & $13(48)$ \\
\hline \multirow[t]{2}{*}{$10^{\circ} \mathrm{C}$} & EFS30 & 8 & $16(38)$ & 13 & $18(39)$ & 20 & $51(41)$ \\
\hline & EFS40 & 10 & $10(40)$ & 7 & $44(54)$ & 16 & $50(38)$ \\
\hline
\end{tabular}

*Survival was assessed by determining the percentage of blastocysts re-expanded (A) within $16 \mathrm{~h}$ and (B) within $48 \mathrm{~h}$ of culture. Seven to ten embryos were placed in each straw, and the number of replicates was $4-6$. Figures in parentheses are the total numbers of blastocysts treated.

All the rates were significantly $(P<0.01)$ different from control, in which $100 \%$ (40 of 40 ) of embryos survived after being kept at each temperature for $30 \mathrm{~min}$. 
Table 4. Percentage survival of expanded mouse blastocysts vitrified in EFS40 by a two-step method after pretreatment at $20^{\circ} \mathrm{C}^{*}$

\begin{tabular}{|c|c|c|c|c|c|c|c|}
\hline \multicolumn{2}{|c|}{ Pretreatment } & \multicolumn{6}{|c|}{ Exposure time in EFS40 } \\
\hline \multirow{2}{*}{$\begin{array}{l}\text { Concentration of } \\
\text { ethylene glycol }(\%)\end{array}$} & \multirow{2}{*}{$\begin{array}{l}\text { Time } \\
\text { (min) }\end{array}$} & \multicolumn{2}{|c|}{$0.5 \mathrm{~min}$} & \multicolumn{2}{|c|}{$1 \mathrm{~min}$} & \multicolumn{2}{|c|}{$2 \mathrm{~min}$} \\
\hline & & A & B & A & B & A & B \\
\hline \multirow[t]{2}{*}{10} & 5 & 69 & $83(58)$ & 56 & $82(55)$ & 32 & $49(41)$ \\
\hline & 10 & 61 & $69(54)$ & 48 & $74(46)$ & 40 & $56(50)$ \\
\hline \multirow[t]{2}{*}{20} & 5 & 49 & $84(57)$ & 30 & $59(44)$ & 22 & $29(45)$ \\
\hline & 10 & 36 & $80(66)$ & 28 & $47(43)$ & 25 & $35(40)$ \\
\hline \multirow[t]{2}{*}{30} & 5 & 24 & $71(41)$ & 40 & $63(40)$ & 9 & $16(45)$ \\
\hline & 10 & 19 & $33(42)$ & 12 & $21(43)$ & 3 & $3(40)$ \\
\hline
\end{tabular}

*Survival was assessed by determining the percentage of blastocysts re-expanded $(A)$ within $16 \mathrm{~h}$ and (B) within $48 \mathrm{~h}$ of culture. Seven to ten embryos were placed in each straw and the number of replicates were 4-7. Figures in parentheses are the total numbers of embryos treated. All the rates were significantly $(P<0.01)$ different from controls, in which $100 \%(40$ of 40$)$ of embryos survived after being kept at $20^{\circ} \mathrm{C}$ for $30 \mathrm{~min}$.

Table 5. Percentage survival of expanded mouse blastocysts vitrified in EFS40 by a two-step method after pretreatment at $25^{\circ} \mathrm{C}^{*}$

\begin{tabular}{|c|c|c|c|c|c|c|c|}
\hline \multicolumn{2}{|c|}{ Pretreatment } & \multicolumn{6}{|c|}{ Exposure time in EFS40 } \\
\hline \multirow{2}{*}{$\begin{array}{l}\text { Concentration of } \\
\text { ethylene glycol } \\
(\%)\end{array}$} & \multirow{2}{*}{$\begin{array}{l}\text { Time } \\
\text { (min) }\end{array}$} & \multicolumn{2}{|c|}{$0.5 \mathrm{~min}$} & \multicolumn{2}{|c|}{$1 \mathrm{~min}$} & \multicolumn{2}{|c|}{$2 \mathrm{~min}$} \\
\hline & & A & B & A & B & A & B \\
\hline \multirow[t]{2}{*}{10} & 5 & 92 & $94(68)$ & $80^{\mathrm{a}}$ & $84^{d}(51)$ & $28^{\mathrm{a}}$ & $30^{\mathrm{a}}(43)$ \\
\hline & 10 & $86^{b}$ & $88^{b}(49)$ & $80^{\mathrm{a}}$ & $88^{b}(49)$ & $22^{\mathrm{a}}$ & $27^{a}(41)$ \\
\hline \multirow[t]{2}{*}{20} & 5 & $72^{\mathrm{a}}$ & $87^{\mathrm{b}}(67)$ & $51^{a}$ & $64^{a}(47)$ & $7^{a}$ & $14^{\mathrm{a}}(42)$ \\
\hline & 10 & $45^{\mathrm{a}}$ & $50^{a}(40)$ & $7^{\mathrm{a}}$ & $12^{a}(43)$ & $7^{\mathrm{a}}$ & $11^{a}(45)$ \\
\hline
\end{tabular}

\footnotetext{
*Survival was assessed by determining the percentage of blastocysts re-expanded (A) within $16 \mathrm{~h}$ and (B) within $48 \mathrm{~h}$ of culture. Nine to 12 embryos were placed in each straw and the number of replicates was 4-7. Figures in parentheses are the numbers of embryos treated. ${ }^{a} P<0.01$, ${ }^{b} P<0.05$ : significantly different from controls, in which $100 \%$ ( 40 of 40 ) of embryos survived after being kept at $25^{\circ} \mathrm{C}$ for $30 \mathrm{~min}$.
}

there was no significance in each variable and in the interaction between the variables.

The survival of embryos after two-step vitrification in EFS40 is summarized in Tables 4 and 5. Embryos suspended in dilute ethylene glycol solution shrank within the zona (Fig. Ia, b) and then regained their volume within 5-10 min (Fig. Ic, d). When embryos were treated at $20^{\circ} \mathrm{C}$, post-warming survival was significantly affected by the three variables, namely, concentration of ethylene glycol $(P<0.01)$, pretreatment time $(P<0.05$, when assessed by $48 \mathrm{~h}$ of culture) and exposure time in EFS40 $(P<0.01)$, although there was no interaction between these variables. Compared with the survival after one-step vitrification (Table 3), higher survival rates were obtained, especially when embryos had been pretreated in a dilute ethylene glycol solution ( 10 or $20 \%$ ) for $5 \mathrm{~min}$, followed by brief exposure $(0.5 \mathrm{~min})$ to EFS40 (49-69\% when assessed by $16 \mathrm{~h}$ of culture, and $83-84 \%$ when assessed by $48 \mathrm{~h}$ of culture) (Table 4 ). When the temperature was increased to $25^{\circ} \mathrm{C}$, post-warming survival was again affected by concentration of ethylene glycol $(P<0.01)$, pretreatment time $(P<0.05)$ and exposure time in EFS40 $(P<0.01)$, with an interaction between ethylene glycol concentration and pretreatment time $(P<0.05)$. Compared with the data at $20^{\circ} \mathrm{C}$ (Table 4), higher proportions (80-92\%) of the embryos that had been pretreated in $10 \%$ ethylene glycol followed by short ( 0.5 or $1 \mathrm{~min}$ ) exposure to EFS40 re-expanded quickly (within $16 \mathrm{~h}$ of culture). The highest value $(92 \%)$ was obtained when the embryos had been pretreated in $10 \%$ ethylene glycol for $5 \mathrm{~min}$ followed by $0.5 \mathrm{~min}$ of exposure to EFS40, and the rate reached $94 \%$ when assessed after $48 \mathrm{~h}$ of culture (Table 5); these rates were not significantly different from those of control embryos.

To examine developmental potential in vivo, embryos were pretreated with $10 \%$ ethylene glycol for $5 \mathrm{~min}$ at $25^{\circ} \mathrm{C}$ and vitrified in EFS40 after $0.5 \mathrm{~min}$ of exposure. In total, 188 cryopreserved embryos were transferred to 16 recipients, of which 13 $(81 \%)$ became pregnant; 12 of these animals delivered 84 (36 
female and 48 male) live young and 1 stillborn fetus on days 19-21. One pregnant recipient was killed on day 22 , and two well-developed live fetuses and one dead fetus were found in the uterus. In controls, 132 fresh embryos were transferred to 11 recipients, in total; all of them became pregnant, and they delivered 78 ( 33 female and 45 male) live young and two stillborn fetuses. The proportion of full-term young/embryos in the cryopreserved group was $58 \%$ ( 88 of 152), when expressed on the basis of the number of embryos transferred to recipients that became pregnant. This proportion was not significantly different from that for the control $(61 \% ; 80$ of 132).

\section{Discussion}

Expanded blastocysts were first collected from superovulated animals. However, the number of normal embryos was small and the developmental stage was variable. Expanded blastocysts were then collected from naturally mated females; the developmental stage was rather uniform, but the number of collected embryos was restricted. Morulae were therefore collected from superovulated animals, and cultured until they expanded. Data were presented disregarding the source of embryos, as no effects of superovulation and embryo culture on survival were found.

Compared with the results of a similar toxicity test on mouse morulae, which were able to survive up to $5 \mathrm{~min}$ of exposure to EFS solution (Kasai et al., 1990), expanded blastocysts must be more sensitive to this solution, namely a high concentration of ethylene glycol, than are morulae. This injury must have been caused either by the chemical toxicity of ethylene glycol or by the osmotic stress that occurred during removal of the permeated ethylene glycol from the embryos. However, as the permeability of a cryoprotectant increases as the developmental stage proceeds (Mazur et al., 1976), and as the volume of each cell constituting the blastocyst is smaller than that in the morula, osmotic stress is a less probable explanation for the injury. Rather, the intracellular concentration of ethylene glycol in the blastocyst would be expected to increase more rapidly than in the morula, and this might promote the toxic effect.

The highest survival rate obtained in the one step vitrification method was $66 \%$ with 2 min of exposure to EFS 40 at $20^{\circ} \mathrm{C}$ (Table 3), but this rate is lower than that obtained with morulae vitrified in the same conditions (98\%; Kasai et al., 1990). One factor restricting the survival would be the toxic effects of EFS40, which began to appear during $2 \mathrm{~min}$ of exposure at $20^{\circ} \mathrm{C}$. The other factor would be insufficient permeation of ethylene glycol, since less permeable conditions, such as shorter exposure, lower temperature and lower concentrations of ethylene glycol, resulted in poorer survival after vitrification. The blastocyst differs structurally from the morula in that it has a fluid-filled blastocoel. When mouse blastocysts with various blastocoel volumes were vitrified or underwent very rapid freezing, survival rates decreased as the blastocoel enlarged (Shaw et al., 1991; Miyake et al., in press). It has been shown that the inclusion of a macromolecule in a solution facilitates vitrification (Fahy et al., 1984). There are various macromolecules in the cytoplasm, whereas Ficoll is present outside the embryo. In the blastocoel, however, there must be few macromolecules, and, possibly, sufficient permeation of ethylene glycol is required for the vitrification of the cavity; insufficient permeation is likely to lead to the formation of ice crystals in the cavity, which must reduce the post-warming survival. For the permeation, however, ethylene glycol must first penetrate into the cells and then into the cavity, which may require a certain time. Yet, the toxic effects of the cryoprotectant to the embryos must be avoided during this exposure time.

In the next series of vitrification tests, we therefore first suspended the embryos in a dilute, and thus less toxic, ethylene glycol solution for permeation of ethylene glycol into the blastocoel. Embryos suspended in $10 \%$ or $20 \%$ ethylene glycol generally regained their isotonic volume within $5-10 \mathrm{~min}$, both at 20 and $25^{\circ} \mathrm{C}$, which indicates that ethylene glycol permeated fully into the blastocoel during this pretreatment period. As expected, higher levels of survival were obtained after vitrification if the following exposure time to EFS40 was limited. These results strongly support the interpretation outlined above, i.e. that expanded blastocysts can survive vitrification if (1) the toxic action of the cryoprotectant is avoided, and (2) sufficient ethylene glycol permeates into the embryo, possibly into the blastocoel.

The ambient temperature of $25^{\circ} \mathrm{C}$ was more suitable than $20^{\circ} \mathrm{C}$ for embryo treatment by the two-step method, if the periods of pretreatment and exposure to EFS40 were short ( $5 \mathrm{~min}$ and $0.5-1 \mathrm{~min}$, respectively). Because the permeability of a cryoprotectant increases as the temperature rises, further permeation of ethylene glycol after exposure of the embryos to EFS40 would appear to be favourable for their survival. However, the reduced survival noted after longer $(2 \mathrm{~min})$ exposure to EFS 40 at $25^{\circ} \mathrm{C}(19-30 \%)$ suggests that the toxic effect of the cryoprotectant is also greater at this temperature than at $20^{\circ} \mathrm{C}$.

Using a vitrification solution containing $25 \%$ glycerol and $25 \%$ propylene glycol, various investigators have attempted to vitrify different stages of mouse embryos by a similar two-step method; however, the survival of blastocysts was found to be lower than that of morulae (Scheffen et al., 1986; Bielanski, 1987; Valdez et al., 1990). Although these authors did not examine precise conditions for the pretreatment and exposure to the vitrification solution, it would appear that the ethylene glycol-based vitrification solution used in the study reported here, which yielded high survival, has the advantages of lower toxicity and higher permeability than the solution used by other workers.

Landa (1982) reported that the optimal day for pseudopregnant animals to receive transfers of day 4 mouse blastocysts was day 2 for frozen-thawed embryos and day 3 for fresh embryos, since frozen-thawed embryos required about $48 \mathrm{~h}$ for the resumption of normal developmental potential. In the study reported here, although all the embryos were transferred to day 3 recipients, the proportion of embryos that developed into fullterm young was not different from that of controls, showing that embryos were less stressed by our two-step method of vitrification. The fact that these embryos had re-expanded quickly (within $16 \mathrm{~h}$ ) also indicates that they were less stressed.

The present results show that it is possible to vitrify expanded mouse blastocysts without significant loss of viability, both in vitro and in vivo. For high survival, embryos have to be exposed to cryoprotectants in two steps; however the 5 min pretreatment followed by $0.5 \mathrm{~min}$ exposure to the vitrification solution at room temperature is a simple procedure. It is expected that the present vitrification method using EFS40 will be suitable for embryos of various species which have large blastocoels. 
This work was supported by a grant-in-aid for scientific research from the Ministry of Education, Science and Culture, Japan. We thank $\mathrm{K}$. Kato and Y. liguni for help with the analysis of the data.

\section{References}

Bielanski A (1987) Survival in vitro of zona pellucida-free mouse embryos after cooling by conventional two-step or vitrification methods Cryo-Letters $\mathbf{8}$ 294-301

Bilton RJ and Moore NW (1976) In vitro culture, storage and transfer of goat embryos Australian Journal of Biological Science 29 125-129

Douchi O, Takakura H and Imai K (1990) Transfer of bovine embryos cryopreserved by vitrification Japanese Journal of Animal Reproduction 36 69-72

Fahy GM, MacFarlane DR, Angell CA and Meryman HT (1984) Vitrification as an approach to cryopreservation Cryobiology 21 407-426

Gordon I and Lu KH (1990) Production of embryos in vitro and its impact on livestock production Theriogenology 33 77-87

Goto K, Kajihara Y, Kosaka S, Koba M, Nakanishi Y and Ogawa K (1988) Pregnancies after co-culture of cumulus cells with bovine embryos derived from in-vitro fertilization of in-vitro matured follicular oocytes joumal of Reproduction and Fertility $83753-758$

Hsu T, Yamakawa H, Yamanoi J and Ogawa S (1986) Survival and transfer test of mouse early embryos frozen by vitrification method Japanese Joumal of Animal Reproduction 32 106-109

Kasai M, Komi JH, Takakamo A, Tsudera H, Sakurai T and Machida T (1990) A simple method for mouse embryo cryopreservation in a low toxicity vitrification solution, without appreciable loss of viability Joumal of Reproduction and Fertility 89 91-97

Kono $\mathrm{T}$ and Tsunoda $\mathrm{Y}$ (1987) Frozen storage of mouse embryos by vitrification Japanese Joumal of Animal Reproduction 33 77-81

Landa V (1982) A simplified method for freezing mouse blastocysts Folia Biologica 28 266-273

Leibfried-Rutiedge ML, Crister ES, Parrish JJ and First NL (1989) Theriogenology 31 61-74

Massip A, Van Der Zwalmen P and Leroy F (1984) Effect of stage of development on survival of mouse embryos frozen-thawed rapidly Cryobiology $\mathbf{2 1}$ 574-577

Massip A, Van Der Zwalmen P, Scheffen B and Ectors F (1986) Pregnancies following transfer of cattle embryos preserved by vitrification Cryo-Letters 7 $270-273$
Matsumoto T, Ishiwata M, Yamanoi J, Yamakawa H, Kondo Y, Kawate S and Ogawa S (1987) Effect of sucrose dilution on survival of mouse early embryos after being frozen by vitrification method Japanese Journal of Animal Reproduction 33 200-205

Mazur P, Rigopoulos N, Jackowski SC and Leibo SP (1976) Preliminary estimates of the permeability of mouse ova and early embryos to glycerol Biophysical Joumal 16 232a (Abstract)

Miyake T, Kasai M, Zhu SE, Sakurai T and Machida T Vitrification of mouse oocytes and embryos at various stages in an ethylene glycol-based solution by a simple method Theriogenology (in press)

Nagashima H, Kato Y, Yamakawa Hr Matsumoto T and Ogawa S (1989) Changes in freezing tolerance of pig blastocysts in peri-hatching state Japanese Journal of Animal Reproduction 35 130-134

Nakagata N (1989) Survival of mouse embryos derived from in vitro fertilization after ultrarapid freezing and thawing Journal of Mammalian Ova Research 6 23-26

Rall WF (1987) Factors affecting the survival of mouse embryos cryopreserved by vitrification Cryobiology 24 387-402

Rall WF and Fahy GM (1985) Ice-free cryopreservation of mouse embryos at $-196^{\circ} \mathrm{C}$ by vitrification Nature $313573-575$

Scheffen B, Van Der Zwalmen P and Massip A (1986) A simple and efficient procedure for preservation of mouse embryos by vitrification Cryo-Letters 7 260-269

Schiewe MC, Rall WF, Stuart LD and Wildt DE (1991) Analysis of cryoprotectant, cooling rate and in situ dilution using conventional freezing or vitrification for cryopreserving sheep embryos. Theriogenology 36 279-293

Shaw JM, Diotallevi L and Trounson AO (1991) A simple rapid 4.5 M dimethylsulfoxide freezing technique for the cryopreservation of one-cell to blastocyst stage preimplantation mouse embryos Reproduction Fertility and Development 3 621-626

Toyoda $Y$ and Chang MC (1974) Fertilization of rat eggs in vitro by epididymal spermatozoa and the development of eggs following transfer Journal of Reproduction and Fertility 36 9-22

Valdez CA, Mazni OA, Takahashi Y, Hishinuma M and Kanagawa H (1990) Effects of equilibration time, precooling and developmental stage on the survival of mouse embryos cryopreserved by vitrification Theriogenology 33 627-636

Whittingham DG (1971) Survival of mouse embryos after freezing and thawing Nature 233 125-126

Whittingham DG, Leibo SP and Mazur P (1972) Survival of mouse embryos frozen to $-196^{\circ} \mathrm{C}$ and $-269^{\circ} \mathrm{C}$ Science $178411-414$

Wilmut I and Rowson LEA (1973) Experiments on the low-temperature preservation of cow embryos Veterinary Record 92 686-690 